\title{
Chapter 5 \\ Prostate Cancer in US Latinos: What Have We Learned and Where Should We Focus Our Attention
}

\author{
Mariana C. Stern
}

\section{Prostate Cancer Among Latinos}

After skin cancer, prostate cancer (PCa) is the most commonly diagnosed cancer among Latino men, with approximately 13,000 cases diagnosed every year in the United States; 1800 Latino men die of PCa every year, making it the fourth leading cause of cancer death among Latinos [1]. PCa is also the most common cancer among non-Latino men, although the incidence rates are higher among non-Latino White (NLW) men and highest among non-Latino Black (NLB) men. In spite of the high burden of PCa in the United States and many other Western countries, there are few established risk factors, and even fewer are modifiable and can be targeted for cancer prevention. Most PCa will be diagnosed in men with localized disease ( $~ 80 \%$ of men), most of whom will have indolent disease, although a small minority will not. Distinguishing clinically significant from clinically insignificant cancer is one of the key challenges that men with prostate cancer face [2-4]. Across the continuum from PCa etiology to PCa survival, there are several other challenges and knowledge gaps, which overall are larger for Latino men, who are greatly understudied. We summarize below some of the salient findings about the characteristics of PCa in US Latinos along this continuum and highlight the unique challenges faced by this population and that deserve further study.

\footnotetext{
M. C. Stern $(\bowtie)$

Departments of Preventive Medicine and Urology, Keck School of Medicine, University of Southern California, Los Angeles, CA, USA

Norris Comprehensive Cancer Center, Keck School of Medicine, University of Southern California, Los Angeles, CA, USA

e-mail: marianas@usc.edu
} 


\section{Prostate Cancer Incidence and Etiology}

The incidence of PCa in US Latino men is 9\% lower than NLW men; however, the incidence observed among US Latino men is higher than the incidence among men in most Latin American countries, which show wide differences in incidence and mortality across countries [5]. Studies done among various migrant populations have shown increases of PCa among US immigrants in comparison with their countries of origin [6]. It is not clear whether these increases are exclusively due to increased detection of $\mathrm{PCa}$ in the United States or changes in environmental factors or a combination of both.

Few established risk factors for PCa are age, African ancestry, family history of PCa, and genetic susceptibility markers identified among NLW and NLB populations $[7,8]$. However, all these factors together explain a very small proportion of the variability of PCa incidence. Several modifiable risk factors have been reported for which the evidence is still inconclusive; however, they deserve consideration as probable PCa risk factors. Among them are body fatness [9], red meat [10], calcium, vitamin D, and lycopene [11]. Less than 2000 Latinos have been included in epidemiological studies in the United States; thus, the knowledge gap for PCa etiology in Latinos is larger than for other racial/ethnic groups. Among the few studies that included Latino men, positive associations were reported for some of the same risk factors reported among non-Latino individuals such as obesity [12], alcohol [13], genetic variants [14], and diets high in red meat cooked at high temperatures and meat mutagens [15]. In addition, positive associations were reported uniquely among Latinos, such as exposure to agrichemicals and PCa risk $[12,16]$, and inverse associations between high intake of legumes and soy products were stronger among Latinos [13, 17].

Most PCa diagnoses are triggered by elevated PSA detected through routine screening, although the landscape of PCa detection is currently changing given the original 2012 recommendation against PSA-based screening from the U.S. Preventive Services Task Force (USPSTF), which in 2018 has evolved into mutual decision between patients and their doctors [18]. These newer recommendations are directly aligned with what the American Urologic Association (AUA) has recommended since 2012 which is sharing decision-making for men aged 55-69 years considering PSA screening, taking into account individual risk factors (e.g., African American, positive family history) $[19,20]$. Thus, even though PSA testing nationwide has decreased, debate on the value of PSA screening continues, and the effects of its reduction in use are still too early to detect with current cancer registries data. Importantly, Latino men show lower rates of use of PSA screening [21-23] than NLW men, associated with these lower rates of screening are low PCa literacy and overall low educational status $[24,25]$, as well as specific Latino values (e.g., fatalism) [25] and lack of health insurance [26]. It is not clear if lower screening alone can explain the reduced incidence of PCa compared to NLW men. To consider, disparities in incidence are also observed when considering aggressive disease only, which is less likely to be detected by PSA, suggesting that other factors may explain 
the reduced incidence among Latinos and remain to be uncovered [27]. Socioeconomic status (SES) is an important modifier of PCa risk, with men in the lowest SES categories having the lowest $\mathrm{PCa}$ incidence and differences being more pronounced for Latinos [27].

A key challenge in understanding cancer determinants among US Latinos is the fact that they constitute a highly heterogeneous population. Latinos are a highly admixed population given the history of colonization of the Americas; all Latinos are descendants from generations of admixture among European, Amerindian, and/ or African ancestral populations, with varying degrees of admixture across different Latin American countries. Further, there are differences due to local traditions, culture, lifestyle, and prevalence of various environmental agents [28, 29]. In the United States, this heterogeneity is greater, because US Latinos might be foreignborn with various degrees of acculturation to the US lifestyle, or they might be US-born first or subsequent generation with Latino parents or grandparents of same or different Latino origin or with only one Latino parent/grandparent. Therefore, Latinos are likely to be among the most heterogeneous ethnic groups in the United States. In spite of this, they are typically considered as one single group in cancer studies. Therefore, estimates of incidence and cancer characteristics might not be representative of all US Latinos [29].

There is accumulating evidence that cancer incidence differs by Latino subpopulations defined by country/region of origin [30-33] or genetic ancestry [29]. Specifically for PCa, Latinos of Mexican origin have been reported to have the lowest incidence among Latinos, and definitively lower than NLW. Caribbean Latinos, such as Cuban and Puerto Rican Latinos, have higher incidence; in fact, Puerto Ricans in Florida were reported to have higher incidence than NLWs [31-33]. Moreover, Latinos living in Florida were reported to have higher incidence of PCa than their counterparts living in their countries or regions of ancestral origin [32]. Similarly, Puerto Ricans living in the island were reported to have lower PCa incidence rates than those living in the mainland United States [34] and lower than US Latinos overall [35]. Recently, we conducted analyses of PCa among Latinos living in California using California Cancer Registry, and in agreement with previous findings, we observed that $\mathrm{PCa}$ incidence rates were lowest among Mexican and Central American Latinos and highest among South American Latinos (unpublished results). In agreement with previous findings considering SES, Mexican and Central American Latinos in California have greater proportion of low SES, whereas South Americans have greater proportion of higher SES. However, estimates by country or region of origin must be interpreted with caution. Whereas algorithms that capture Latino status in cancer registry data are efficient and have good specificity [36, 37], and algorithms are available to obtain nativity status (US- vs. foreign-born status) [38], data for country of origin is missing for a large subset of Latinos identified in cancer registries. Some of this might be due to lack of inquiry from health professionals at the time of diagnosis and treatment, and some might be due to the fact that US-born Latinos, who might be fully acculturated to US lifestyle and might be several generations of US Latinos, might no longer identify with one particular Latin American country of origin, and thus this information might not come up 
during their cancer diagnosis and care. In addition, some foreign-born Latinos may not volunteer this information due to fears triggered by their immigration status. In the California Cancer Registry, more than $70 \%$ of Latinos with missing country of origin were US-born Latinos [30]. If missingness is independent of country/region of origin, and systematic across all Latinos, then the disparities observed across Latino subpopulations would still be true. However, if missingness differed by country/region of origin, this could lead to biases in incidence rates and artifactual disparities by country/region of origin. The lack of systematic efforts to enrich data collection of Latino origin in cancer registries is an important gap that needs to be addressed to facilitate studies of cancer patterns in Latinos. For Asian populations, some cancer registries currently track subpopulation information by country of origin. Similar approaches could be developed for Latino subpopulations.

Few studies have interrogated the role of genetic ancestry and PCa risk among US Latinos. One study done in Puerto Rico reported a lack of association between global African ancestry and PCa risk; however, they replicated an association between a single-nucleotide polymorphism (SNP) of African ancestral origin and PCa risk, suggesting possible associations with African local ancestry and PCa risk that deserve further investigation [39]. To our knowledge, no studies have investigated the role of Indigenous American ancestry and PCa risk, and whether the presence of specific alleles of Indigenous American origin might explain the lower risk of PCa among some Latinos, as it has been reported for breast cancer [40].

\section{Clinical Presentation of PCa Among Latinos}

Most PCa tumors are diagnosed by 12-core systematic random prostate needle diagnostic biopsy, which can miss areas of more advanced disease already present in the prostate in as high as $30 \%$ of patients, thus introducing under-staging and undergrading error at the time of diagnosis [41-43]. PCa biopsies are used not only for cancer staging but also for treatment decision-making [44]. Patients diagnosed with clinically insignificant disease, typically Gleason 6 and no biopsy core with more than $5 \mathrm{~mm}$ of cancer, will likely be offered to avoid treatment and enroll in active surveillance, whereas those with clinically significant cancer, those with Gleason 7 or higher or any Gleason with biopsy cores with more than $5 \mathrm{~mm}$ of cancer, will be offered definitive treatment. If the diagnostic biopsy missed the most aggressive part of the tumor, patients diagnosed with clinically insignificant cancer might be at risk by not choosing adequate treatment. The rate of misclassification of PCa biopsy has been reported to be higher among African-American men compared to NLW men $[45,46]$, and it has been proposed that this could be due to higher proportion of anterior tumors, which are more likely to be missed by random systematic biopsies $[46,47]$. The proportion of anterior tumors and rate of biopsy misclassification among Latinos are understudied. One study, of modest sample size, compared the Gleason grade at biopsy to the one obtained at surgery and reported that the rate of misclassification in PCa biopsy among Latinos was $\sim 36 \%$, which was in between 
the rate in NLWs $(27 \%)$ and NLBs ( 52\%) [48]. Interestingly, the majority of tumors with misclassification had anterior localization [48]. Recently, in analyses done with data from the California Cancer Registry from 1995 to 2012, we observed that foreign-born Latinos had higher rate of upgrade from biopsy to resection than NLWs and even NLBs, with Mexicans showing the highest proportion of misclassification $(\sim 30 \%)$ and Caribbean Latinos showing a proportion that was even lower than NLWs $(\sim 18 \%)$ (unpublished results). These results are intriguing and deserve further investigation. If a higher proportion of anterior tumors localization was confirmed among Latinos, along with higher rate of misclassification on biopsy, this would strongly advocate for a greater proportion of Latinos receiving more accurate biopsies coupled with imaging, such as magnetic resonance imaging (MRI)-guided targeted biopsies, which can more accurately identify clinically significant cancer and sampling error [49-51]. However, these procedures are currently costly and are only available at specialized centers. Given that a great proportion of US Latinos have low SES, they may lack insurance, or their insurance may not cover these procedures, which are not yet standard of care. More research in this area is needed to advocate for changes in healthcare coverage.

Analyses done with California Cancer Registry data showed that foreign-born Latinos had greater proportion of advanced stage at diagnosis than US-born Latinos [52]. Moreover, our recent analyses in the same California registry (1995-2012) showed comparable proportion of high grade at diagnosis, positive lymph nodes, and metastasis as NLBs, with disparities observed by country of origin among foreign born (unpublished results). A separate report using SEER data showed that Latinos had higher proportion of metastatic disease at diagnosis than NLBs and NLWs [53].

\section{PCa Treatment Patterns Among Latinos}

The Prostate Cancer Outcomes Study reported that Latinos received radical prostatectomy in greater proportions than NLWs and NLBs and received radiation therapy in lower proportion [54]. Among Latinos in California, foreign-born Latinos were reported to be more likely to undergo surgery than US-born Latinos and less likely to receive radiation [52]. Our own analyses within the California Cancer Registry showed that foreign-born Latinos, Mexicans, Central Americans, and South Americans had the highest proportion of surgery utilization (unpublished findings). In contrast, a study done in Texas reported that Latinos were less likely to receive radical prostatectomy, or radiation therapy, than NLWs [55]. Further, a study done using data from the National Cancer Database reported that a lower proportion of Latinos than NLWs received radical prostatectomy and that a greater proportion than NLWs received radiation or androgen deprivation therapy [56]. The different conclusions between these studies might be partially driven by different definitions of Latino status and consideration of nativity. 
Our analyses also showed that Latinos, especially foreign-born, had a greater proportion of men without any treatment reported (unpublished results). This might be indicative of higher proportion of men choosing active surveillance, although we cannot confirm this. Analyses using SEER data show that along with NLBs, Latinos are more likely to enroll in active surveillance instead of choosing treatment [5759], and an association has been reported between low-income patients and selection of watchful waiting $[60,61]$. Alarmingly, Latinos under active surveillance seem to be less likely to receive medical monitoring [57, 62], and we recently reported that Latinos under active surveillance were more likely to be lost to followup than NLWs [63]. These findings are concerning and require additional studies to identify determinants of lack of adherence to active surveillance in order to reduce loss to follow-up and possible disparities in overall survival.

\section{Survival and Mortality}

Historically, US Latinos have been reported to have lower mortality rates from PCa than NLWs [1]. However, this finding might be heavily influenced by the heterogeneity within Latinos and may not accurately reflect the experience of all Latinos in the United States. In Florida, Latinos from the Dominican Republic were reported to have the highest PCa mortality rates, followed by South Americans, Central Americans, Cubans, Puerto Ricans, NLWs, and then Mexicans [64]. A recent study from California and Texas focused exclusively on US-born Latinos and reported mortality rates for PCa that were comparable to those among NLWs in both states [65]. These studies highlight the importance of considering Latino national origin and the biases that are introduced when this consideration is not given. Disparities have been reported between US and foreign-born Latinos; foreign-born Latinos living in high enclave neighborhoods had better survival than US-born Latinos in similar neighborhoods, whereas both had comparable survival if they lived in low enclave/higher SES neighborhoods [52]. It is possible that among foreign-born Latinos, specially low SES Latinos, there might be missing data on mortality if many of them return to their home countries ("salmon hypothesis") to seek care or to die back home, or if missing social security numbers impair proper tracking of death via vital statistics. These and other related circumstances may bias estimates of mortality among Latinos yielding the false notion that survival patterns are more favorable, as discussed by Pinheiro et al. in previous studies [64, 65] and in Chap. 2 in this same issue.

In terms of survival patterns, a study done with SEER data, taking into account possible clinical determinants, concluded that when considering all Latino men combined, there were no differences in survival with NLWs; however, when considering country of origin, several disparities emerged, with Puerto Ricans having less favorable survival than NLWs [66]. In recent analyses using the California Cancer Registry, we did not find differences in survival between Caribbean Latinos and NLWs, or between US-born Latinos and NLWs, and we only observed marginally 
improved survival for South American Latinos (unpublished results). Lack of consideration of nativity may explain these disparate results between studies. Overall, results from foreign-born Latinos need to be interpreted with caution given the large number of missing data, potential issues with missing social security numbers, and uncertainty over final place of death.

\section{Final Conclusions and Key Knowledge Gaps to Address}

Research on PCa in Latinos lags behind our current knowledge for other racial/ ethnic groups. This is a disparity of great public health relevance given that PCa is the number one cancer that affects Latino men and that Latinos are the largest and fastest growing minority population in the United States, and majority population in some US regions, such as California. Among the key knowledge gaps we need to address are the following:

- Great need for more epidemiological studies with adequate risk factor data including Latinos; currently, there are less than 2000 individuals ascertained across studies in the United States.

- Data collection on Latino national origin needs to be improved at all levels so that cancer registries can allow for more accurate analyses taking into account Latino heterogeneity.

- Analyses of the role of genetic ancestry and PCa risk among Latinos are needed, as these studies may help inform some of the cancer incidence findings.

- The tumor landscape of Latino men is largely unknown, as scarcely any Latinos have been included in ongoing efforts such as The Cancer Genome Atlas. Moreover, patterns of tumor localization need to be understood in order to improve PCa detection strategies among Latinos accordingly.

- More studies are needed on patterns of care and adherence to active surveillance among Latinos, with emphasis on their determinants, to design culturallysensitive interventions to address any disparities.

- Similar to other cancers, clinical trials focused on novel treatments for advanced PCa need to include more Latinos.

\section{References}

1. Siegel RL, Fedewa SA, Miller KD, Goding-Sauer A, Pinheiro PS, Martinez-Tyson D, et al. Cancer statistics for Hispanics/Latinos, 2015. CA Cancer J Clin. 2015;65(6):457-80.

2. Klotz L. Active surveillance for prostate cancer: a review. Curr Urol Rep. 2010;11(3):165-71.

3. Tosoian JJ, Trock BJ, Landis P, Feng Z, Epstein JI, Partin AW, et al. Active surveillance program for prostate cancer: an update of the Johns Hopkins experience. J Clin Oncol. 2011;29(16):2185-90. 
4. van den Bergh RC, Essink-Bot ML, Roobol MJ, Wolters T, Schroder FH, Bangma CH, et al. Anxiety and distress during active surveillance for early prostate cancer. Cancer. 2009;115(17):3868-78.

5. GLOBOCAN 2012 v1.0. Cancer incidence and mortality worldwide [database on the Internet]. International Agency for Research on Cancer. 2013. Accessed Apr 2018.

6. Angwafo FF. Migration and prostate cancer: an international perspective. J Natl Med Assoc. 1998;90(11 Suppl):S720-3.

7. Benafif S, Eeles R. Genetic predisposition to prostate cancer. Br Med Bull. 2016;120(1):75-89.

8. Conti DV, Wang K, Sheng X, Bensen JT, Hazelett DJ, Cook MB, et al. Two novel susceptibility loci for prostate cancer in men of African ancestry. J Natl Cancer Inst. 2017;109:8.

9. World Cancer Research Fund/American Institute for Cancer Research. Continuous update project report: diet, nutrition, physical activity, and prostate cancer; 2014.

10. Bouvard V, Loomis D, Guyton KZ, Grosse Y, Ghissassi FE, Benbrahim-Tallaa L, et al. Carcinogenicity of consumption of red and processed meat. Lancet Oncol. 2015;16(16):1599-600.

11. Lin PH, Aronson W, Freedland SJ. An update of research evidence on nutrition and prostate cancer. Urol Oncol. 2019;37(6):387-401.

12. Strom SS, Yamamura Y, Flores-Sandoval FN, Pettaway CA, Lopez DS. Prostate cancer in Mexican-Americans: identification of risk factors. Prostate. 2008;68(5):563-70.

13. Park S-Y, Haiman CA, Cheng I, Park SL, Wilkens LR, Kolonel LN, et al. Racial/ethnic differences in lifestyle-related factors and prostate cancer risk: the Multiethnic Cohort Study. Cancer Causes Control. 2015;26(10):1507-15.

14. Cheng I, Chen GK, Nakagawa H, He J, Wan P, Laurie CC, et al. Evaluating genetic risk for prostate cancer among Japanese and Latinos. Cancer Epidemiol Biomarkers Prev. 2012;21(11):2048-58.

15. Joshi AD, Corral R, Catsburg C, Lewinger JP, Koo J, John EM, et al. Red meat and poultry, cooking practices, genetic susceptibility and risk of prostate cancer: results from a multiethnic case-control study. Carcinogenesis. 2012;33(11):2108-18.

16. Cockburn M, Mills P, Zhang X, Zadnick J, Goldberg D, Ritz B. Prostate cancer and ambient pesticide exposure in agriculturally intensive areas in California. Am J Epidemiol. 2011;173(11):1280-8.

17. Park SY, Murphy SP, Wilkens LR, Henderson BE, Kolonel LN, Multiethnic Cohort S. Legume and isoflavone intake and prostate cancer risk: the Multiethnic Cohort Study. Int J Cancer. 2008;123(4):927-32.

18. Screening for Prostate Cancer. U.S. Preventive Services Task Force. 2012. www.uspreventiveservicestaskforce.org/prostatecancerscreening.htm. Accessed Dec 2018.

19. Greene KL, Albertsen PC, Babaian RJ, Carter HB, Gann PH, Han M, et al. Prostate specific antigen best practice statement: 2009 update. J Urol. 2009;182(5):2232-41.

20. AUA Speaks Out Against USPSTF Recommendations. AUA, www.auanet.org. 2012. www. auanet.org/content/health-policy/government-relations-and-advocacy/in-the-news/uspstf-psarecommendations.cfm. Accessed Dec 2018.

21. Haque R, Van Den Eeden SK, Jacobsen SJ, Caan B, Avila CC, Slezak J, et al. Correlates of prostate-specific antigen testing in a large multiethnic cohort. Am J Manag Care. 2009;15(11):793-9.

22. Hosain GM, Sanderson M, Du XL, Chan W, Strom SS. Racial/ethnic differences in predictors of PSA screening in a tri-ethnic population. Cent Eur J Public Health. 2011;19(1):30-4.

23. Zhou J, Enewold L, Peoples GE, McLeod DG, Potter JF, Steele SR, et al. Colorectal, prostate, and skin cancer screening among Hispanic and White non-Hispanic men, 2000-2005. J Natl Med Assoc. 2011;103(4):343-50.

24. Reyes-Ortiz CA, Camacho ME, Amador LF, Velez LF, Ottenbacher KJ, Markides KS. The impact of education and literacy levels on cancer screening among older Latin American and Caribbean adults. Cancer Control. 2007;14(4):388-95.

25. Coronado G, Thompson B. Rural Mexican American men's attitudes and beliefs about cancer screening. J Cancer Educ. 2000;15(1):41-5. 
26. Valdovinos C, Penedo FJ, Isasi CR, Jung M, Kaplan RC, Giacinto RE, et al. Perceived discrimination and cancer screening behaviors in US Hispanics: the Hispanic Community Health Study/Study of Latinos Sociocultural Ancillary Study. Cancer Causes Control. 2016;27(1):27-37.

27. Yin D, Morris C, Allen M, Cress R, Bates J, Liu L. Does socioeconomic disparity in cancer incidence vary across racial/ethnic groups? Cancer Causes Control. 2010;21(10):1721-30.

28. Salari K, Choudhry S, Tang H, Naqvi M, Lind D, Avila PC, et al. Genetic admixture and asthma-related phenotypes in Mexican American and Puerto Rican asthmatics. Genet Epidemiol. 2005;29(1):76-86.

29. Stern MC, Fejerman L, Das R, Setiawan VW, Cruz-Correa MR, Perez-Stable EJ, et al. Variability in cancer risk and outcomes within US Latinos by national origin and genetic ancestry. Curr Epidemiol Rep. 2016;3:181-90.

30. Stern MC, Zhang J, Lee E, Deapen D, Liu L. Disparities in colorectal cancer incidence among Latino subpopulations in California defined by country of origin. Cancer Causes Control. 2016;27(2):147-55.

31. Howe HL, Lake A, Schymura MJ, Edwards BK. Indirect method to estimate specific Hispanic group cancer rates. Cancer Causes Control. 2009;20(7):1215-26.

32. Pinheiro PS, Sherman RL, Trapido EJ, Fleming LE, Huang Y, Gomez-Marin O, et al. Cancer incidence in first generation U.S. Hispanics: Cubans, Mexicans, Puerto Ricans, and new Latinos. Cancer Epidemiol Biomarkers Prev. 2009;18(8):2162-9.

33. Howe HL, Wu X, Ries LA, Cokkinides V, Ahmed F, Jemal A, et al. Annual report to the nation on the status of cancer, 1975-2003, featuring cancer among U.S. Hispanic/Latino populations. Cancer. 2006;107(8):1711-42.

34. Ho GY, Figueroa-Valles NR, De La Torre-Feliciano T, Tucker KL, Tortolero-Luna G, Rivera WT, et al. Cancer disparities between mainland and island Puerto Ricans. Rev Panam Salud Publica. 2009;25(5):394-400.

35. Soto-Salgado M, Suarez E, Torres-Cintron M, Pettaway CA, Colon V, Ortiz AP. Prostate cancer incidence and mortality among Puerto Ricans: an updated analysis comparing men in Puerto Rico with US racial/ethnic groups. P R Health Sci J. 2012;31(3):107-13.

36. NAACCR Latino Research Work Group. NAACCR Guideline for Enhancing Hispanic/Latino Identification: revised NAACCR Hispanic/Latino Identification Algorithm [NHIA v2.2]. Springfield: North American Association of Central Cancer Registries; 2009.

37. Group NRaEW. NAACCR guideline for enhancing Hispanic/Latino identification: revised NAACCR Hispanic/Latino identification algorithm [NHIA v.2.2.1]. Springfield; 2011.

38. Gomez SL, Quach T, Horn-Ross PL, Pham JT, Cockburn M, Chang ET, et al. Hidden breast cancer disparities in Asian women: disaggregating incidence rates by ethnicity and migrant status. Am J Public Health. 2010;100(Suppl 1):S125-31.

39. Irizarry-Ramírez M, Kittles RA, Wang X, Salgado-Montilla J, Nogueras-González GM, Sánchez-Ortiz R, et al. Genetic ancestry and prostate cancer susceptibility SNPs in Puerto Rican and African American men. Prostate. 2017;77(10):1118-27.

40. Fejerman L, Ahmadiyeh N, Hu D, Huntsman S, Beckman KB, Caswell JL, et al. Genome-wide association study of breast cancer in Latinas identifies novel protective variants on 6q25. Nat Commun. 2014;5:5260.

41. Cohen MS, Hanley RS, Kurteva T, Ruthazer R, Silverman ML, Sorcini A, et al. Comparing the Gleason prostate biopsy and Gleason prostatectomy grading system: the Lahey Clinic Medical Center experience and an international meta-analysis. Eur Urol. 2008;54(2):371-81.

42. Conti SL, Dall'era M, Fradet V, Cowan JE, Simko J, Carroll PR. Pathological outcomes of candidates for active surveillance of prostate cancer. J Urol. 2009;181(4):1628-33; discussion $33-4$

43. Carter HB. Active surveillance for prostate cancer: an underutilized opportunity for reducing harm. J Natl Cancer Inst Monogr. 2012;2012(45):175-83.

44. Ukimura O, Coleman JA, de la Taille A, Emberton M, Epstein JI, Freedland SJ, et al. Contemporary role of systematic prostate biopsies: indications, techniques, and implications for patient care. Eur Urol. 2013;63(2):214-30. 
45. Sundi D, Ross AE, Humphreys EB, Han M, Partin AW, Carter HB, et al. African American men with very low-risk prostate cancer exhibit adverse oncologic outcomes after radical prostatectomy: should active surveillance still be an option for them? J Clin Oncol. 2013;31(24):2991-7.

46. Sanchez-Ortiz RF, Troncoso P, Babaian RJ, Lloreta J, Johnston DA, Pettaway CA. AfricanAmerican men with nonpalpable prostate cancer exhibit greater tumor volume than matched white men. Cancer. 2006;107(1):75-82.

47. Sundi D, Kryvenko ON, Carter HB, Ross AE, Epstein JI, Schaeffer EM. Pathological examination of radical prostatectomy specimens in men with very low risk disease at biopsy reveals distinct zonal distribution of cancer in black American men. J Urol. 2014;191(1):60-7.

48. Kryvenko ON, Lyapichev K, Chinea FM, Prakash NS, Pollack A, Gonzalgo ML, et al. Radical prostatectomy findings in White Hispanic/Latino men with NCCN very low-risk prostate cancer detected by template biopsy. Am J Surg Pathol. 2016;40(8):1125-32.

49. Siddiqui MM, Rais-Bahrami S, Turkbey B, George AK, Rothwax J, Shakir N, et al. Comparison of MR/ultrasound fusion-guided biopsy with ultrasound-guided biopsy for the diagnosis of prostate cancer. JAMA. 2015;313(4):390-7.

50. Baco E, Rud E, Ukimura O, Vlatkovic L, Svindland A, Matsugasumi T, et al. Effect of targeted biopsy guided by elastic image fusion of MRI with 3D-TRUS on diagnosis of anterior prostate cancer. Urol Oncol. 2014;32(8):1300-7.

51. Kasivisvanathan V, Rannikko AS, Borghi M, Panebianco V, Mynderse LA, Vaarala MH, et al. MRI-targeted or standard biopsy for prostate-cancer diagnosis. $\mathrm{N}$ Engl J Med. 2018;378:1767-77.

52. Schupp CW, Press DJ, Gomez SL. Immigration factors and prostate cancer survival among Hispanic men in California: does neighborhood matter? Cancer. 2014;120(9):1401-8.

53. Akinyemiju T, Sakhuja S, Waterbor J, Pisu M, Altekruse SF. Racial/ethnic disparities in de novo metastases sites and survival outcomes for patients with primary breast, colorectal, and prostate cancer. Cancer Med. 2018;7(4):1183-93.

54. Harlan LC, Potosky A, Gilliland FD, Hoffman R, Albertsen PC, Hamilton AS, et al. Factors associated with initial therapy for clinically localized prostate cancer: prostate cancer outcomes study. J Natl Cancer Inst. 2001;93(24):1864-71.

55. des Bordes JKA, Lopez DS, Swartz MD, Volk RJ. Sociodemographic disparities in cure-intended treatment in localized prostate cancer. J Racial Ethn Health Disparities. 2018;5(1):104-10.

56. Wang EH, Yu JB, Abouassally R, Meropol NJ, Cooper G, Shah ND, et al. Disparities in treatment of patients with high-risk prostate cancer: results from a population-based cohort. Urology. 2016;95:88-94.

57. Shavers VL, Brown ML, Potosky AL, Klabunde CN, Davis WW, Moul JW, et al. Race/ethnicity and the receipt of watchful waiting for the initial management of prostate cancer. J Gen Intern Med. 2004;19(2):146-55.

58. Moses KA, Orom H, Brasel A, Gaddy J, Underwood W 3rd. Racial/ethnic differences in the relative risk of receipt of specific treatment among men with prostate cancer. Urol Oncol. 2016;34(9):415 e7-e12.

59. Shavers VL, Brown ML. Racial and ethnic disparities in the receipt of cancer treatment. J Natl Cancer Inst. 2002;94(5):334-57.

60. Klabunde CN, Potosky AL, Harlan LC, Kramer BS. Trends and black/white differences in treatment for nonmetastatic prostate cancer. Med Care. 1998;36(9):1337-48.

61. Krupski TL, Kwan L, Afifi AA, Litwin MS. Geographic and socioeconomic variation in the treatment of prostate cancer. J Clin Oncol. 2005;23(31):7881-8.

62. Shavers VL, Brown M, Klabunde CN, Potosky AL, Davis W, Moul J, et al. Race/ethnicity and the intensity of medical monitoring under 'watchful waiting' for prostate cancer. Med Care. 2004;42(3):239-50.

63. Fonseca-Nunes A, Jakszyn P, Agudo A. Iron and cancer risk-a systematic review and meta-analysis of the epidemiological evidence. Cancer Epidemiol Biomarkers Prev. 2014;23(1):12-31. 
64. Pinheiro PS, Callahan KE, Siegel RL, Jin H, Morris CR, Trapido EJ, et al. Cancer mortality in Hispanic ethnic groups. Cancer Epidemiol Biomark Prev. 2017;26(3):376-82.

65. Pinheiro PS, Callahan KE, Gomez SL, Marcos-Gragera R, Cobb TR, Roca-Barcelo A, et al. High cancer mortality for US-born Latinos: evidence from California and Texas. BMC Cancer. 2017;17(1):478.

66. Velasquez MC, Chinea FM, Kwon D, Prakash NS, Barboza MP, Gonzalgo ML, et al. The influence of ethnic heterogeneity on prostate cancer mortality after radical prostatectomy in Hispanic/Latino men: a population-based analysis. Urology. 2018;117:108-14.

Open Access This chapter is licensed under the terms of the Creative Commons AttributionNonCommercial 4.0 International License (http://creativecommons.org/licenses/by-nc/4.0/), which permits any noncommercial use, sharing, adaptation, distribution and reproduction in any medium or format, as long as you give appropriate credit to the original author(s) and the source, provide a link to the Creative Commons license and indicate if changes were made.

The images or other third party material in this chapter are included in the chapter's Creative Commons license, unless indicated otherwise in a credit line to the material. If material is not included in the chapter's Creative Commons license and your intended use is not permitted by statutory regulation or exceeds the permitted use, you will need to obtain permission directly from the copyright holder.

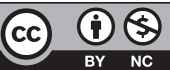

